\title{
FACILITATING THE FUNDING FOR THE CONSERVATION THROUGH TRADEABLE DEVELOPMENT RIGHTS AN APPROACH THROUGH MAPPING AND ANALYZING THE BUILT HERITAGE AT AHMEDABAD, INDIA
}

\author{
Rajdeep Routh $^{\mathrm{a}, *}$, Piyush Shah ${ }^{\mathrm{b}}$ \\ ${ }^{a}$ Researcher, Design Innovation and Crafts Resource Centre, CEPT University, Ahmedabad, India \\ routhrajdeep@gmail.com \\ ${ }^{\mathrm{b}}$ Geospatial Specialist, TARU Leading Edge Pvt. Ltd., Gandhinagar, India \\ piyushsh18@gmail.com
}

KEY WORDS: Heritage conservation, Tradable Development Rights, Funding mechanisms, Stakeholder Involvement, Inventory management, Open source GIS

\begin{abstract}
:
In India, most of the built heritage is still retained by private ownership, who usually are un inproficient to provide the monetary support for the upkeep of the building. In such a scenario, the property goes into deterioration and is gradually lost. In response to this, the Ahmedabad Urban Develepment Authority (AUDA) have introduced a policy named Tradable Development Rights (TDR) for listed structures within the historic core of Ahmedabad, which will help in generating revenue for conservation of the built heritage. This paper discusses an apparatus which will assist the process of TDR by forming a common platform between the stakeholders to increase efficiency in the procurement and transaction procedure. The system comprises of a procedure which puts all the listed properties on an interactive map, classified according to the grade assigned to each along with the present physical condition of the building, along with information such as the heritage value, contact details, available FSI through TDR and at what amount. The map has been developed using Open Source GIS, and will act as a model for mapping and managing the inventory generated for Ahmedabad. This will help the builders approach the properties which have been graded in terms of importance and urgency as well as simultaneously providing public awareness by through necessary information which the property owner should know to avail the monetary benefits through TDR. The paper also highlights a comparative analysis and benefits of procuring the FSI available through TDR for the historic core.
\end{abstract}

\section{INTRODUCTION}

During the past few years, the focus on heritage and its management by urban locoal bodies have increased considerably. Although the focus is majorly confined to the physical conservation of individual buildings of public importance and not for those with private ownership. To address this concern, the Ahmedabad Urban Development Authority (AUDA) at have proposed a policy named Tradable Development Rights (TDR) for private properties within the historic core of Ahmedabad. The policy will try and facilitate the conservation by allowing the owners to trade a pre-assigned Floor Spacing Index (FSI) and generate revenue. However the policy of TDR, being very fruitful in terms of generating revenue for cultural heritage, may falter if it doesn't provide the funds on time for properties who have the urgent need of restoration. Thus, without the proper awareness of the detailed inventory or an efficient platform to chanellize the transactions, the agencies availing the benefits of the policy may end up overlooking the buildings which are in worst physical condition. This paper will hence discuss an apparatus which will assist the process of TDR and help the stakeholders make better use of it through an interactive map.

The paper talks about a prototype which comprises of the listed properties displayed on an detailed and user friendly interactive map. At present a map is developed for a sample study with the use of a tool named Open Source GIS, and will act as a model for mapping the built heritage and managing the inventory generated for Ahmedabad. The properties would be classified according to the grade assigned to each along with the physical condition of the building. The listing will also incorporate all the information required for an individual property such as the location, heritage value, physical area, available FSI through TDR and the potential revenue generated. The structure will also act towards public awareness and will include all the necessary information and procedures which the property owner should know to avail the monetary benefits through TDR. Thus, the output will produce a comprehensive and meticulously catalogued information, through an interactive map, essential to facilitate the funding for conservation of heritage properties and would be helpful both for the property owners and builders.

\section{AHMEDABAD AND IT'S HERITAGE}

The present day Ahmedabad is a bustling metropolitan city, with an area of 464 Sq.Kms. and is home to five and a half million people. The origins of the present day historic settlement of Ahmedabad can be traced back to AD 1411, when Ahmed Shah started the erection of a fortification on the site of Asawal, the earlier settlement. Today, the core walled city occupies an area of $4 \mathrm{Sq} . \mathrm{Km}$ (Figure 1). Right from its inception, the city has seen progressive development and has 
been willing to adapt to new trends. This trait is clearly visible in all the contemporary influences which all the dynasties followed right from the Sultanate era to the days of the British rule. The old city of Ahmedabad is a closely knit settlement with narrow meandering streets, along with chowks and markets to punctuate them. The old precinct showcases a unique amalgamation of Hindu and Islamic cultural influences, which is clearly evident on the architectural heritage of the city.

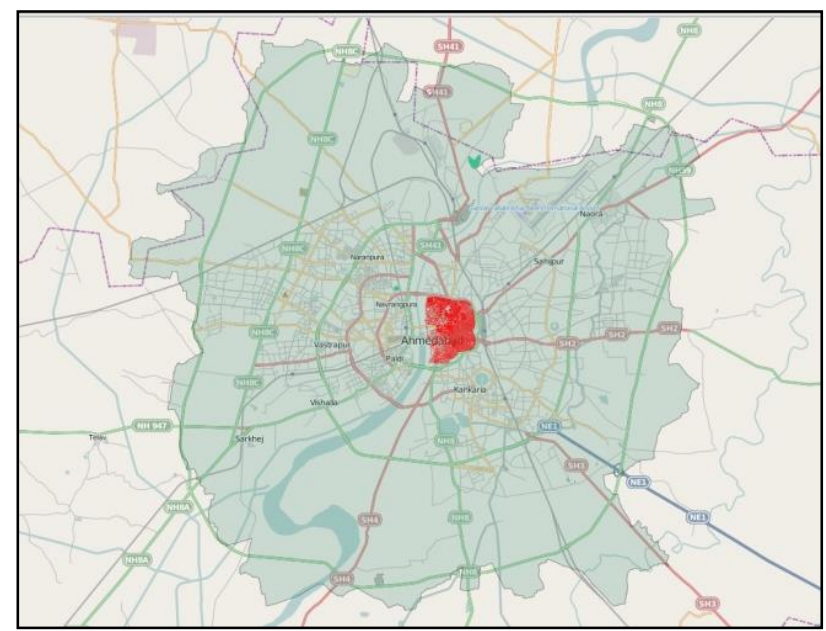

Figure 1. The historic core within the Ahmedabad Municipal Limits

The architectural heritage of Ahmedabad has steadily evolved over the past 600 years, and the historic quarters are adorned by palatial havelis, houses with elaborately carved wooden facades and religious structures. Although there are various forms of built heritage, belonging to different era, the significance lies with the domestic architecture. This built environment, along with the arrow streets and the chowks, form a significant part of the old precinct and give it the distinct character. Most of these structures still survive today, but facing constant dilapidation due to various factors. The recent years have seen the historic settlement face unrelenting pressures from the commercial activities and developments happening within it, and has undergoing a constant change due to these intrusions. The historic core has also been witnessing a change in the demographic character of the residents. This is happening as the natives are moving towards the newer parts of the city, leaving the buildings to be inhabited by the people who have migrated from nearby towns and villages. As these new residents are not culturally or emotionally attached to the heritage, they show the least interest towards the maintenance of the structures. These factors, along with the lack of proper policies and funding mechanism, have led to an extensive loss of the built heritage.

In the recent years, the urban authorities in cooperation with local participation and non-governmental organizations have started taking measures to curtail the damages and take positive steps towards the conservation of the cultural heritage and the character it provides. The measures have led to proposal of many policies for providing the conservation of the heritage, and the efforts have in-turn led the historic city of Ahmedabad being nominated in the tentative list of UNESCO World Heritage Cities for 2011.

\section{TRADEABLE DEVELOPMENT RIGHTS}

The Tradable Development Rights (TDR) is a policy in which a property owner can sell the development rights to another person or agency, who may use that for development of buildings in other parts of the city. TDR has been used by the various urban local bodies worldwide, for projects ranging from road widening to slum development to heritage conservation, and in turn provides financial incentives for the property owners. Thus the policy has always provided an effective alternative towards urban growth and its management. The strategy saw its initial use in Europe in 1950's to develop agricultural land, and got introduced in India only by 1980's.

The TDR is also effective in the conservation of built heritage, and provides the property owner with financial support in return of selling the unutilized Floor Spacing Index (FSI) for the property. The system has been creatively used for the conservation of cultural heritage in countries like United States and Canada to preserve its built heritage and landmark buildings. The use of TDR for heritage conservation in India is a very current trend, and has been most effectively used for the city of Mumbai. An intelligent application of the policy, along with a well-managed inventory, can generate significant amount of funds for the buildings which are undergoing dilapidation.

\subsection{TDR Policy for Ahmedabad}

Ahmedabad consists of a large repository of cultural heritage, both tangible and intangible. Over the 600 years of its existence, the historic urban center has witnessed a constant accumulation of architectural heritage and range from elaborate religious buildings to residences with exquisitely carved wooden facades. Amongst all the types of built heritage visible within the city, the residential architecture gives a distinct character to the city and is of high prominence. Most of this built heritage, even today, is still retained by private ownership and if the owner is incapable of providing the monetary support for the upkeep of the building, it goes into deterioration and is gradually lost. This highlights the need for policies and mechanisms developed for facilitating the conservation of private properties. With this intention at the forefront, AUDA has introduced the policy of Tradable Development Rights (TDR) for listed structures within the historic core of Ahmedabad.

The policy will try and facilitating the owners to be able to trade a pre-assigned Floor Spacing Index (FSI) and generate revenue for conservation of their property. According to TDR, all properties within the walled city have been assigned tradable FSIs, according to the heritage value of the property. The properties which have the highest heritage value will be assigned maximum tradable FSI of 0.5 , along with 0.3 for other buildings. These tradable FSI will be available for trading at $40 \%$ less than that of the existing Jantri rates for the respective old city area.To support this Ahmedabad Municipal Corporation (AMC) has developed a detailed inventory of heritage properties which are mostly residential and comprises properties spread across 18 pols or wards. According to the previous inventory, the policy is set to benefit a total 12,000 heritage structures within the historic core. The new listing assigns a specific heritage value to each building, based on the architectural and historical value, as well as the condition of the building. Other than that, the listing also mentions any significant character visible in the building. The policy will have the least interference of the governing authorities, other than monitoring the use of funds, and the property owners can be directly approached by the developers. To further facilitate the strategy, the ready reckoner rate, popularly known as Jantri, has also been fixed at a discounted rate in comparison to other parts of the city. This policy of TDR, apart from helping the 
conservation work, will also benefit the new development in other parts of the city.

According to new draft development plan developed by Ahmedabad Urban Development Authority (AUDA), the city of Ahmedabad is about to see a lot growth and expansion. The new development plan envisions Ahmedabad as a compact city. This strategy will reduce the the urban sprawl of the city and encourage adequate densities by densification of existing areas The new draft plan proposes a Transit Oriented Development, which will witness a major development areas along with Bus Rapid Transit System (BRTS) corridor. The policy also identifies new zones such as Central Business District (CBD) and an Affordable Housing Zone. To suffice all the proposals, AUDA has increased the FSIs for various parts of the city, with the highest permissible FSI being 5.4 for the CBD. This increase in demand of the additional FSI available can also be procured from the heritage structures of the walled city.

With the increase in the permissible FSI for a large section of the city, the developers would be attracted towards the TDR policy for the heritage structures. As the ready reckoner rates proposed for historic core is subsidized, it is beneficial for the developers to procure the required FSI from here instead. Thus, the policy of TDR is very fruitful for many stakeholders including the heritage property owners and the developers. But it may falter without proper knowledge of the heritage buildings which are assigned the rights to trade the FSI and will miss its intention if it doesn't provide funds for the structures which are in urgent need of restorations. Consequently arises a need to develop an apparatus which will assist the stakeholders through an interactive map and manage the inventory of the properties which benefit through TDR.

\section{TRACES}

Tradable Rights And Conservation Enabling System (TRACES) is developed to facilitate the better implementation of the TDR comprises of a procedure which will put all the listed properties on an interactive map. The map would be developed with the use of a tool named OpenGeo Suite, and will act as a model for mapping the built heritage and managing the inventory generated for the historic precinct of Ahmedabad. The properties would be classified according to the grade assigned to each along with the present physical condition of the building. The apparatus gains importance as it involves a listing which includes the physical conditions so the builders can approach the properties, which have urgent need of repairs, first. The listing will also incorporate all the information required for an individual property such as the location, heritage value, building area, available FSI through TDR and at what amount. The application structure will also act towards public awareness and will include all the necessary information and procedures which the property owner should know to avail the monetary benefits through TDR. Thus, the output will produce a comprehensive and meticulously catalogued information, through an interactive map, essential to facilitate the funding for conservation of heritage properties and would be helpful both for the property owners and builders.

With this intention, Khadia, a prominent ward with rich cultural heritage, was selected as a sample study area for understanding the functionality of the application. It is administratively divided into 3 wards, namely Khadia 1, 2 and 3; and occupies almost one-fourth area of the historic core. Khadia is an important historic quarter of the walled city and has always been the hub of cultural activities right through the years. The presence of traditional communities, various types of buildings and the ubiquitous residential structures make Khadia the most significant cultural area of historic Ahmedabad. The precinct at all times been a focal point of cultural development and has given many notable citizens in various fields of study to the city. This area also has a significant number of architectural landmarks, and has some of the best examples of built heritage found in Ahmedabad. The case study area has around 3000 listed heritage buildings, which probably makes it one of the largest surviving repository of the heritage buildings in the walled city (Figure 2).

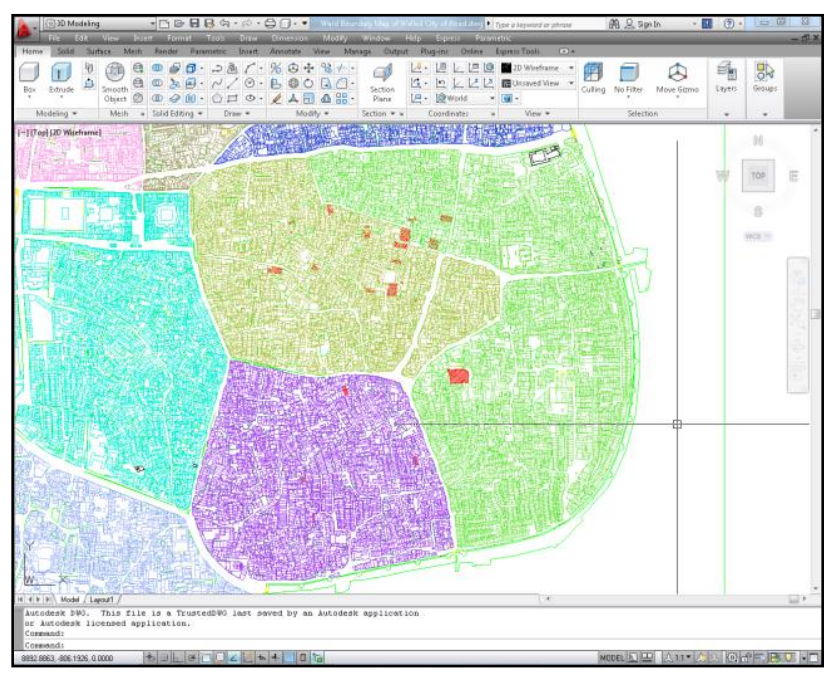

Figure 2. Digital map with heritage buildings for the study area

These structures are further divided into 3 categories according to their heritage and architectural value. For the purpose this proposal, samples have been identified from the large group of houses which showcase the overall nature of the built heritage available for Ahmedabad. The samples were selected according the listed buildings for Khadia, across all the building grades and the condition of the buildings within each category (Table $1)$.

\begin{tabular}{|c|c|c|c|c|}
\hline \multicolumn{5}{|c|}{ Number of Houses } \\
\hline Khadia 1 & Grade1 & Grade 2A & Grade 2B & Total \\
\hline Good & 1 & 4 & 2 & 7 \\
\hline Fair & 11 & 11 & 93 & 115 \\
\hline Bad & 5 & 3 & 70 & 78 \\
\hline Total & 17 & 18 & 165 & $\mathbf{2 0 0}$ \\
\hline
\end{tabular}

Table 1. Selection of sample for Khadia 1

This inventory also identifies the condition of the building for each of the grades and are listed as either good, fair or bad. After studying the number of properties, they were divided into a matrix consisting of nine building conditions and weightage in percentile was assigned to each category according to the number of listed structures they had.

\subsection{Data Collection}

The data collected for the purpose of the study is largely divided into two categories, spatial and non-spatial data. The spatial data mainly consisted of the map showing the properties within the historic city, and the non-spatial consisted of the 
information related to the individual properties. For developing the spatial data for the prototype, the map bases were procured for the study area. The maps, which were obtained from the Heritage Cell, Ahmedabad Municipal Corporation (AMC), are the survey drawing prepared for Ahmedabad (Figure 3). The survey drawings for the walled city of Ahmedabad consists of a set of 99 drawings, and were provided in digital form also. The survey sheets indicate all the properties and structures present within the historic core and provides the relevant data for each building, such as the survey number for buildings and the number of floors. The built area for the houses used for sample study were obtained from the digital copies of the survey sheets provided and later correlated with the original survey drawings for any discrepancies.

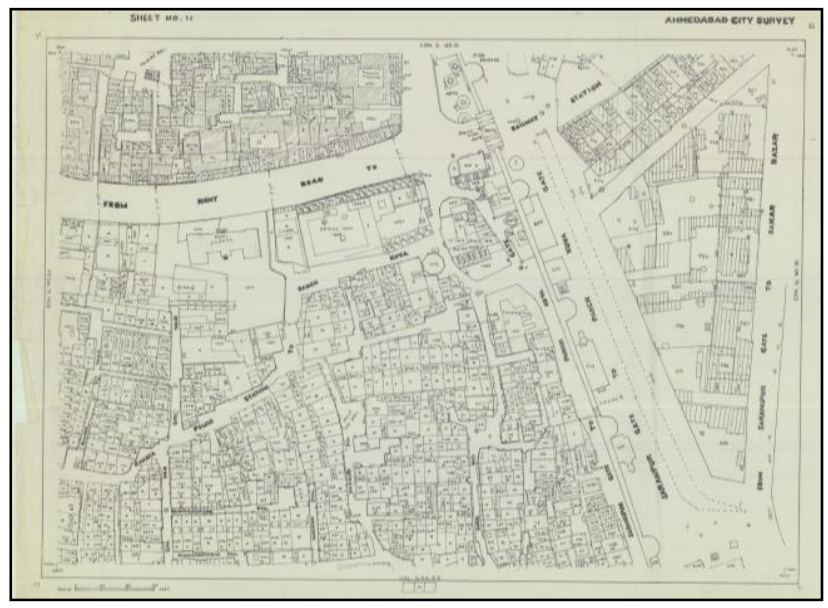

Figure 3. A survey drawing for Ahmedabad

The non-spatial data for developing the model consists of the preliminary list of heritage buildings prepared by the listing prepared by the AMC in 2001, in collaboration with the Government of France. As the current process of listing the heritage building is still under process of generation, this data was used to develop a working prototype of the map application. The listing includes all the 13 administrative wards of the old city area, and provides information such as the survey number, usage of the property, grade and the condition of the condition of the building. The list also comprises of the salient features of the heritage building, along with the number of floors. As per the inventory, the buildings are divided into 3 Grades according to the historical and architectural importance it has. Each grade of building is further categorized into 3 building conditions, namely Good, Fair and Bad. The structures falling under Grade 1 comprise of buildings which are national or historic importance, and display excellent architectural features and material usage, and deserve the most careful preservation. The ready reckoning rates, also known as Jantri rates, for the sampled building were obtained from the Annual Statements of Rates (Draft). The collection of non-spatial data was done from the reports and inventories present on the online portals of the AMC and AUDA.

\subsection{Data Transformation}

The second stage of the process involved the conversion of data to make it compatible towards the usage in map app. After the collection of the spatial data for the city of Ahmedabad, the transformation of these documents happened from the AutoCad (.dxf format) platform to the OpenGeo Suite, along with the use of QuantumGIS (Figure 4). In the initial stages, the spatial data for the whole of the historic core of Ahmedabad was converted for the GIS medium, and later stages saw the amalgamation of spatial and non-spatial data for the selected houses within the area of Khadia.

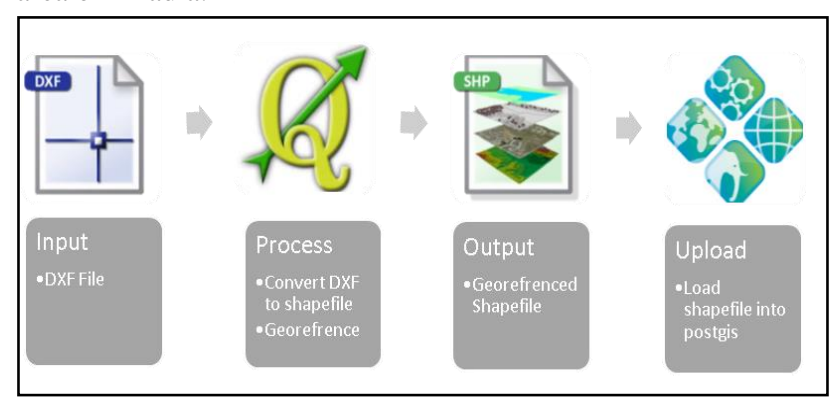

Figure 4. Process diagram of data transformation

The spatial data procured from the AMC, being in vector format and operable in AutoCAD, needed to be converted to a compatible format which could be used for the preparing the map base on GIS software. The vector data was converted from the Data Exchange Format (.dxf) to Shapefile (.shp format) using the Dxf2Shp converter plugin of QuantumGIS. QuantumGIS (QGIS) is an open source desktop geographic information systems (GIS) application that enables data viewing, editing, and analysis possibilities, and can be used across various platforms. AutoCAD being a local software, it is essential to convert the drawing format to shapefile in QGIS to make it readable in various GIS platforms.

The next stage of data transformation involves the georeferencing of the shape files generated, through QGIS. To georeference the shape file, using the control points, the known geographic coordinates of these control points are to be inserted, and choose the coordinate systems and other projection parameters. This forms a very significant step, as it aids the production of shape files into a new map and also link two or more different datasets together by virtue of the fact that they relate to the same geographic locations (Figure 5).

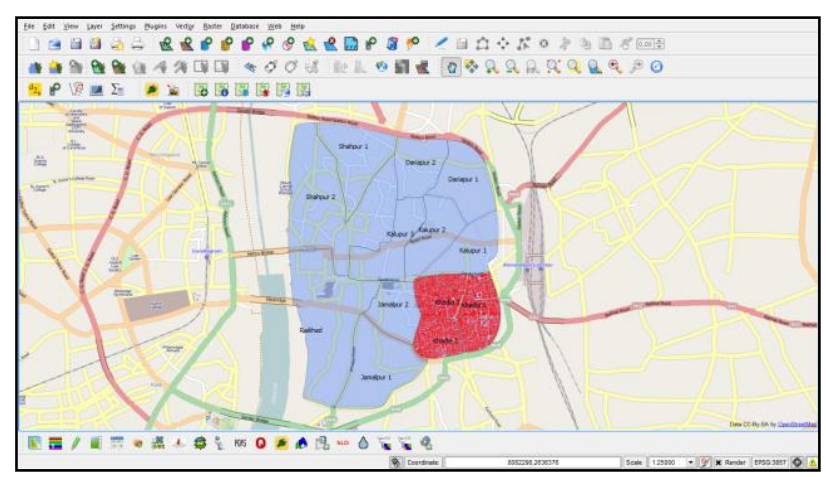

Figure 5. Geo-referenced map of Khadia along with other ward boundaries

Post the process of geo-referencing, all the residences selected as the sample study are searched on the map and marked along with the respective survey numbers. The subsequent stage involves the relating and joining the content of non-spatial data for the selected houses. This database includes items such as survey number, grade and condition of the building, jantri rate, building area and the available tradable FSI. These georeferenced shape files, along with the related attributes, are then loaded onto a spatial database using OpenGeo Suite. The 
OpenGeo Suite is a geospatial software, consisting of spatial database (PostGIS), and includes all the tools necessary to create a full geospatial solution.

\subsection{Data Dissemination}

The last of the activity talks about the dissemination of the dataset produced, to be made available to the stakeholders, is done using the GeoExplorer app of the OpenGeo Suite. GeoExplorer is a web application, based on the GeoExt framework, for composing and publishing maps (Figure 6).

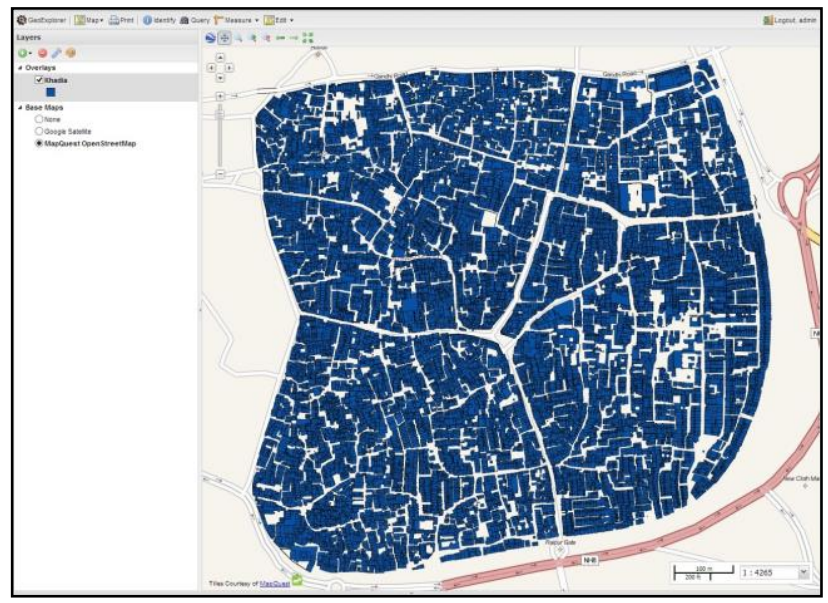

Figure 6. Base map for display on GeoExplorer

The newly created maps can integrated with maps such as Google Maps and OpenStreetMap, and allows the editing of map styles and printing the maps in pdf format. The GeoExplorer is majorly divided into three sections, Map window, Toolbar and Layer panel, which allows the end user to generate queries using various parameters The GeoExplorer application allows the integration of both spatial and non-spatial data in a cohesive manner, and provides the multiple permutation and combination of types of search and analysis. The map allows the stakeholders, especially the developers, to search the properties in various ways according to their needs and requirements. It gives the developer the possibility to search through various filters such as the area needed or the grade of the building and also using multiple parameters (Figure 7).

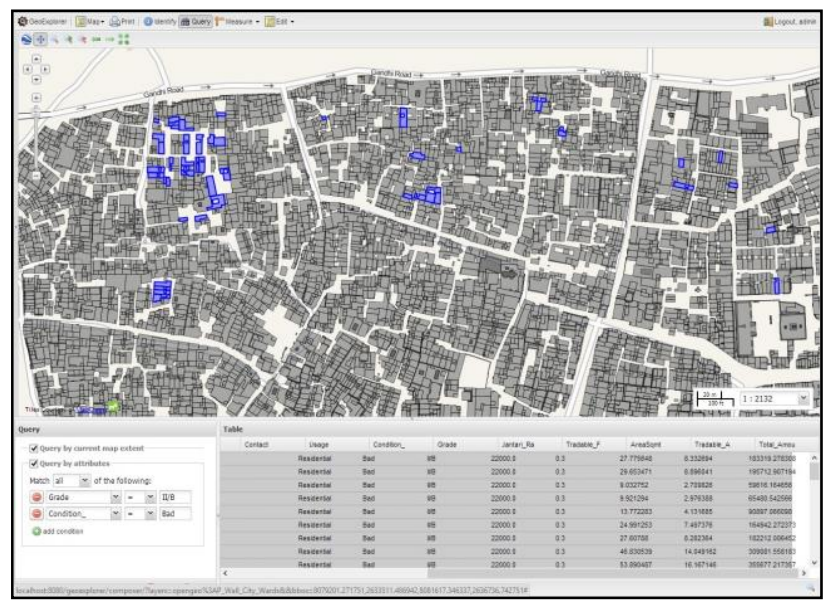

Figure 7. Search result using multiple parameters
They can highlight the heritage properties which have their desired tradable area combined with the condition of the building. Every query highlights the buildings which are bad in physical condition and require urgent repairs, so as to inform the developers of the properties which are in urgent need of the funds (Figure 8).

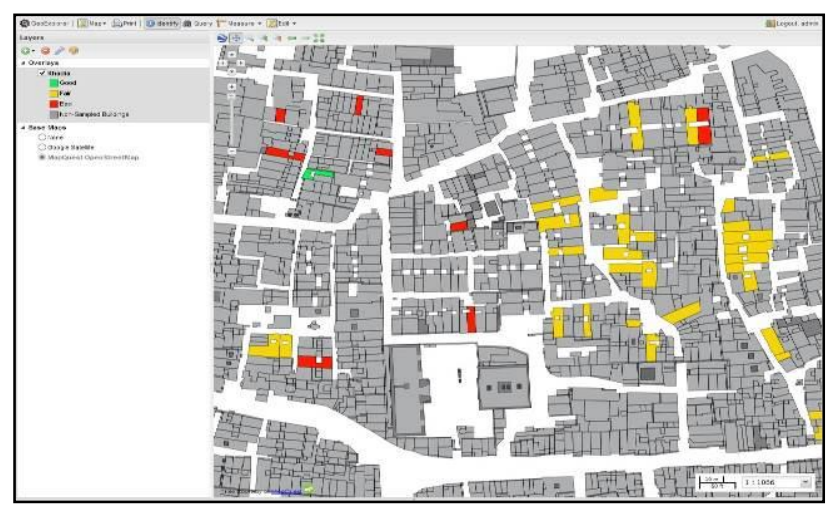

Figure 8. Search highlighting the condition of the buildings

The application allows the user to search the properties from the entire walled city or a particular area, as it allows searching by current map extents (Figure 9).

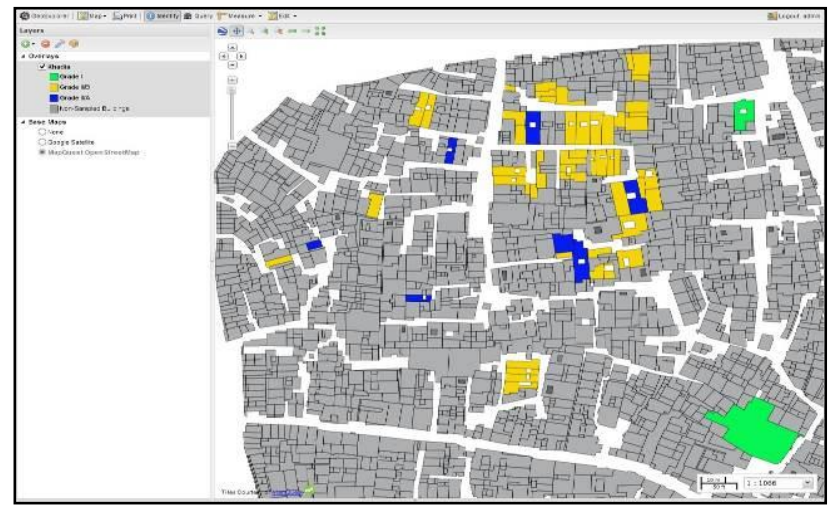

Figure 9. Query generation for a limited area

The application can also be used by the property owners to modify or alter the details about their houses and add additional details. On clicking a query generated property, information card would be displayed which would give all the information required for an individual property such as the heritage value, physical area, available FSI through TDR and at potential revenue (Figure 10). The information card would also provide the contact details to the property owner, so that the developer can directly approach and proceed through the necessary stages of the TDR policy. The card will also provide the link to the online webpage of the TDR policy, which will provide the necessary information regarding the same. The app also provides the facility of printing the search results or saving them in PDF format for future references (Figure 11).

Thus along with highlighting the properties available for the policy of TDR, the interactive map would also maintain an inventory of the heritage properties for the historic city of Ahmedabad. 


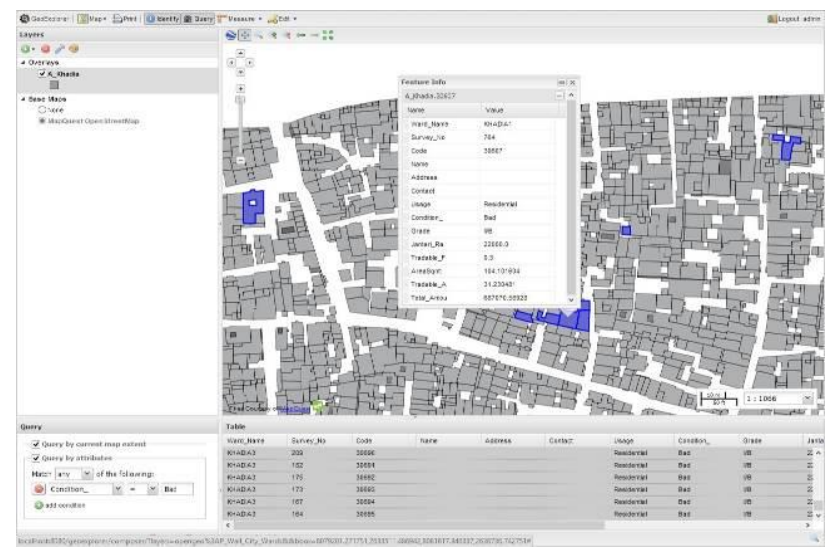

Figure 10. Info card for selected property

\section{CONCLUSION}

Multiple efforts at different levels are being made in Ahmedabad for conservation of its built heritage from Government local bodies, together with catalyzing the conservation at policy levels to NGO's working on ground for the conservation of the built heritage. For effective implementation of the TDR for the built heritage requires a thorough listing process, also maintaining and managing the comprehensive and meticulously catalouged inventory information which can be available to the stakeholders. TRACES intends to provide a common platform to enable smooth and efficient interaction between these stake holders. The application is designed to create direct connection between the builders and the owners of the listed heritage buildings. The system uses both local and web-based GIS systems, and would be helpful for people to use the TDR policy in a comprehensive manner. The application is not only designed to be userfriendly and transparent but also supports the open source forum. The dataset in the application can be extended in different dimensions to facilitate various other policies in the future regarding the conservation and management of built heritage. Development and constant monitoring of such a system would help manage the built heritage of our historic settlements and facilitate various government policies for the conservation of our cultural heritage.

\section{ACKNOWLEDGEMENT}

We want to register our acknowledgements to everyone who has contributed towards the research paper. We would like to especially thank Ms. Dhruma Bhavsar for helping with the analysis of the policy and its benefits for the historic core of Ahmedabad, and also being a constant support. We would also appreciative of the Heritage Cell, Ahmedabad Municipal Corporation for providing us with necessary base data which was of utmost usefulness. We shall also extend our gratitude towards City Heritage Centre, Ahmedabad for the suggestions and data provided.

\section{REFERENCES}

John, P., 2013, February 28. Historic Ahmedabad can draw Rs. 342 crore for conservation. The Times of India. pp. 2.

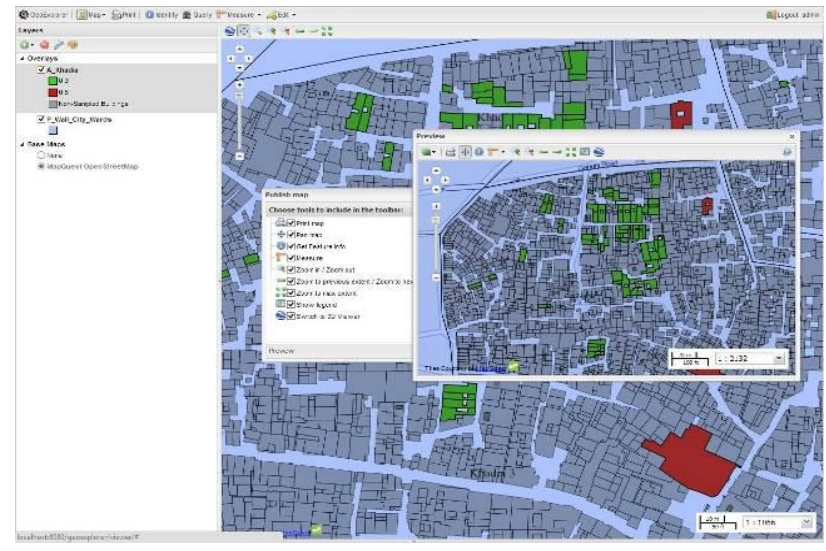

Figure 11. Printing the query generated

Marpakwar, C., 2013, May 10. New heritage rules to improve conservation by rewarding owners. Mumbai Mirror. pp. 3, 8 .

Thara, D., 2013. CONNECTKaro by Embarq India "Draft Development Plan - 2021 (Review) AUDA, January 21, 2013”, Mumbai, India http://www.slideshare.net/EMBARQNetwork/01-d-thara-apriltod-prezi?from_search=4 (03 Jun. 2013).

Ahmedabad Municipal Corporation, 2001. "Preliminary List of Heritage Buildings in The Walled City of Ahmedabad Volume 1", Ahmedabad, India http:// www.egovamc.com/Downloads/Heritage/Volume-I.pdf (28 May. 2013).

Ahmedabad Municipal Corporation, 2001. "Preliminary List of Heritage Buildings in The Walled City of Ahmedabad Volume 2", Ahmedabad, India http:// www.egovamc.com/Downloads/Heritage/Volume-II.pdf (28 May. 2013).

Ahmedabad Municipal Corporation, 2006. "Stamp duty-Annual statement of rates (Draft)", Ahmedabad, India http://www.egovamc.com/gruda/6.Jantri_as_applicable_on_Dt 28th_march_2011.PDF (03 Jun. 2013).

Ho, B. S. F., 2000. The Conservancy Association "Achieving Heritage Conservation in Sustainable Development - Transfer of Development Rights as a Sustainable Solution.”, Kowloon, Hong Kong

http://www.cahk.org.hk/articles/docs/20000510e.pdf (16 May. 2013).

Ahmedabad Urban Development Authority. "Draft Comprehensive Development Plan 2021 ( $2^{\text {nd }}$ Revised) Part 3 General Development Regulations", Ahmedabad, India http://auda.org.in/AudaGdr/ShowPDF.aspx

Pangotra, P., 2008. Financing Techniques and Strategies eor Urban Heritage Conservation. In: Urban Revitalization Perspectives And Initiatives (Management Series). Icfai University Press, Hyderabad, India, pp. 101-110. 